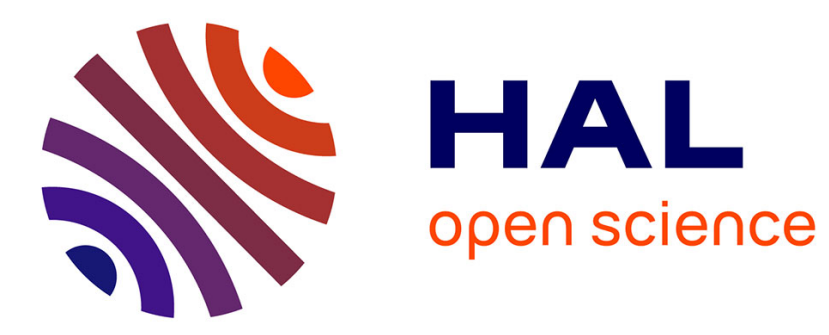

\title{
Synthesis and Characterization of Iodo Derivatives of Bis-salphen Complexes
}

Melia Lacaze, Nathalie Saffon-merceron, Fabien Silly, Jacques Bonvoisin

\section{To cite this version:}

Melia Lacaze, Nathalie Saffon-merceron, Fabien Silly, Jacques Bonvoisin. Synthesis and Characterization of Iodo Derivatives of Bis-salphen Complexes. Journal of Molecular Structure, 2021, 10.1016/j.molstruc.2020.129319 . hal-02949087

\section{HAL Id: hal-02949087 \\ https://hal.science/hal-02949087}

Submitted on 25 Sep 2020

HAL is a multi-disciplinary open access archive for the deposit and dissemination of scientific research documents, whether they are published or not. The documents may come from teaching and research institutions in France or abroad, or from public or private research centers.
L'archive ouverte pluridisciplinaire HAL, est destinée au dépôt et à la diffusion de documents scientifiques de niveau recherche, publiés ou non, émanant des établissements d'enseignement et de recherche français ou étrangers, des laboratoires publics ou privés. 


\section{Journal Pre-proof}

Synthesis and Characterization of lodo Derivatives of Bis-salphen Complexes

Melia Lacaze, Nathalie Saffon-Merceron, Fabien Silly, Jacques Bonvoisin

PII:

DOI:

Reference:

To appear in:

Received date:

Revised date:

Accepted date:
S0022-2860(20)31637-9

https://doi.org/10.1016/j.molstruc.2020.129319

MOLSTR 129319

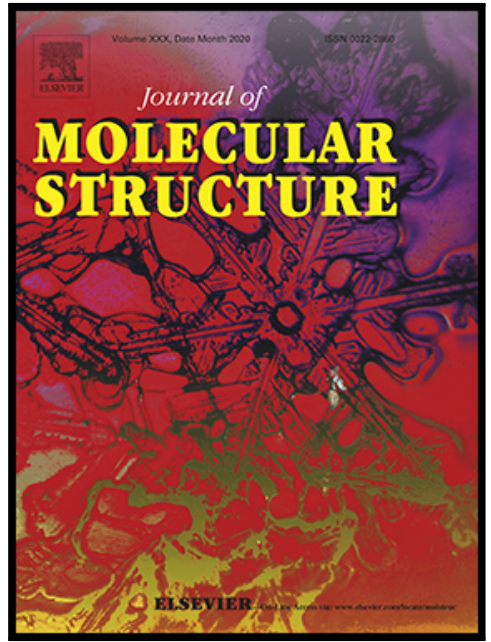

Please cite this article as: Melia Lacaze, Nathalie Saffon-Merceron, Fabien Silly, Jacques Bonvoisin , Synthesis and Characterization of lodo Derivatives of Bis-salphen Complexes, Journal of Molecular Structure (2020), doi: https://doi.org/10.1016/j.molstruc.2020.129319

This is a PDF file of an article that has undergone enhancements after acceptance, such as the addition of a cover page and metadata, and formatting for readability, but it is not yet the definitive version of record. This version will undergo additional copyediting, typesetting and review before it is published in its final form, but we are providing this version to give early visibility of the article. Please note that, during the production process, errors may be discovered which could affect the content, and all legal disclaimers that apply to the journal pertain.

(C) 2020 Published by Elsevier B.V. 
Highlights :

- Candidates for self-assembled halogen-bonded nanoarchitectures

- X-ray structure of iodo derivative of bis-salphen zinc complex 


\section{Synthesis and Characterization of Iodo Derivatives of Bis-salphen Complexes.}

Melia Lacaze ${ }^{a}$, Nathalie Saffon-Merceron ${ }^{b}$, Fabien Silly $^{c}$, Jacques Bonvoisin ${ }^{a, *}$

${ }^{a}$ CEMES, CNRS, UPR 8011, Université de Toulouse, 29 rue Jeanne Marvig, B.P. 94347 Toulouse cedex 4 France

${ }^{b}$ UPS, Institut de Chimie de Toulouse, Université de Toulouse, ICT FR 2599, 118 route de Narbonne, 31062 Toulouse, France

' Université Paris-Saclay, CEA, CNRS, TITANS, 91191 Gif sur Yvette, France

Corresponding author: jacques.bonvoisin@cemes.fr

Abstract: Two new iodo derivatives of bis-salphen zinc complexes [salphen $=\mathrm{N}, \mathrm{N}^{\prime}$ bis(salicylideneimine)-1,2-diaminobenzene] have been synthesized and fully characterized. The ${ }^{1} \mathrm{H}$ NMR, ${ }^{13} \mathrm{C}$ NMR, IR, UV-Vis, TGA, elemental analysis and MALDI mass spectral data of these complexes are presented. In addition, X-Ray single crystal diffraction analysis of complex 1 has been recorded. These two compounds present a great potential interest for generating 2D covalent organic nanoarchitecture.

Keywords: Metal-Salophen complexes / Crystal structure / Zinc / NMR / TGA

1. Introduction

Metal-salphen or bis-salphen are promising molecules for engineering two-dimensional nanomaterials since their planar structure is ideal to favor flat adsorption on surfaces.[1-7] These molecules can be prepared using a one-step process. This makes these compounds accessible, cost-effective synthesis and easy to functionalized. [8] These compounds have surprisingly received little attention as sources of supramolecular planar building blocks $[9,10]$ for engineering complex two-dimensional nanoarchitectures. Directional and selective intermolecular interactions have been successfully exploited to control the lateral arrangement of molecular building blocks. Large-scale two-dimensional organic nanoarchitectures have thus been engineered taking advantage of intermolecular hydrogenbonds [11-14] and halogen bonds. [15-17] Molecular building blocks with halogens also have an interesting potential to create novel on-surface synthesized 2D covalent organic nanoarchitectures. [18-20]

Herein, we present two molecules which are ideal candidates as molecular building block to elaborate complicated self-assembled halogen-bonded nanoarchitectures. [21] These molecules are composed of two iodo derivatives of bis-Zn(II)salphen complexes 1-2 (Scheme 1). These two molecules differ by the position of the iodine atoms on the four external phenyl rings. These different designs are expected to lead to totally different molecular arrangements as it has already been noticed in our precedent work [21]. Indeed, we showed that a tiny modification of the skeleton of the molecule can drastically affect its self-assembly. [21] The synthetic work is presented as well as the ${ }^{1} \mathrm{H} N M R,{ }^{13} \mathrm{C} N M R$, IR, TGA, UV-Vis and MS spectra. The X-Ray analysis of complex $\mathbf{1}$ is also shown. 


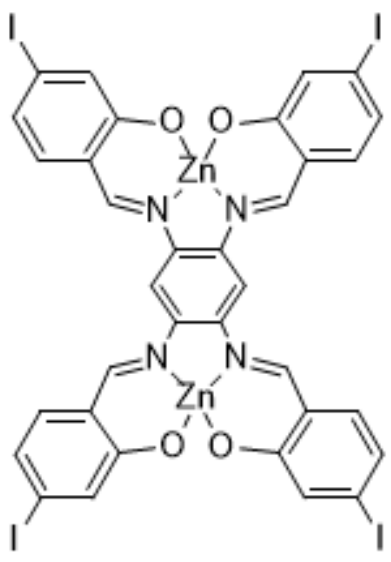

1

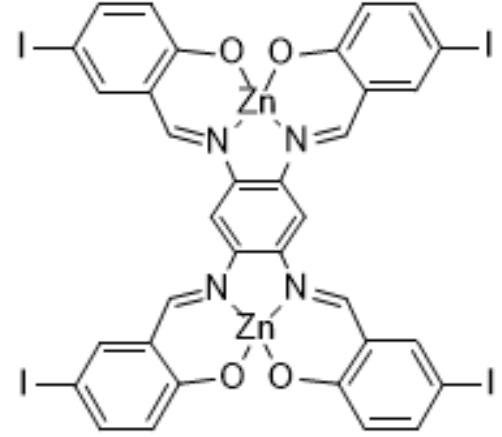

2

Scheme 1

\section{Experimental}

Physical Measurements. IR spectra were measured on a PerkinEImer Spectrum 100 FT-IR spectrometer with samples as $\mathrm{KBr}$ pellets. UV-Vis spectra were recorded on a Varian Cary 5000 spectrophotometer. MS spectra were recorded by the Service de Spectrométrie de Masse of Paul Sabatier University using Waters MALDI micro MX spectrometer for matrix-assisted laser desorption ionization (MALDI; matrix: trans-2-[3-(4-tert-butylphenyl)-2-methyl-2-propenylidene]malonitrile $\quad$ (DCTB); $\quad \lambda=337 \mathrm{~nm}) . \quad \mathrm{NMR}$ experiments were performed at 298K on a Bruker AVANCE I 500MHz spectrometer equipped with a 5 $\mathrm{mm}$ Z-gradient TCl cryoprobe and on a Bruker AVANCE III HD 500MHz equipped with a $5 \mathrm{~mm}$ Z-gradient BBO PRODIGY cryoprobe. Full assignments of ${ }^{1} \mathrm{H}$ and ${ }^{13} \mathrm{C}$ spectra were made with the assistance of COSY, HMBC and HSQC spectra. Coupled TG/DTA measurements were performed on about $15 \mathrm{mg}$ of each sample, using a Setaram-Labsys apparatus, from ambient to $1000{ }^{\circ} \mathrm{C}$. A $100 \mathrm{ml} \mathrm{min}^{-1}$ Helium flow was used and the warming up was realized with a $15^{\circ} \mathrm{C} \mathrm{min}-1$ ramp rate. Mass loss was given with an accuracy done near $0.01 \%$

General methods for the preparation of complexes. All of solvents and materials were used without further purifications. The synthesis of complexes $\mathbf{1}$ and $\mathbf{2}$ follows the procedure given by Kleij et al. [22] The bis-salphen complexes were prepared in a yield of around $60 \%$ by a one-pot protocol consisting of four condensation and two metalation stages. The high selectivity for the targeted complexes 1-2 was obtained by combining the tetramine and $\mathrm{Zn}(\mathrm{OAc})_{2}$ in DMSO to which the salicylaldehyde reagent was added as a solution in the same solvent. Procedures using other solvent as THF or mixture of solvents as THF/MeOH as used in Lin's publication [23] afforded lower yields or intractable mixtures of components.

\subsection{Preparation of complexes 1-2}

2.1.1. Synthesis of complex 1: $\left[\left(\mu_{2}-1,2,4,5\right.\right.$-tetrakis( $N$-(5-iodosalicylidenealdiminato $\left.)\right)$ benzene)bis(N,Ndimethylformamide)-di-zinc(ii)]

To a solution of 1,2,4,5-tetraaminobenzene tetrahydrochloride (100 mg, $0.352 \mathrm{mmol}$ ) and $\mathrm{Zn}(\mathrm{OAc})_{2} .2 \mathrm{H}_{2} \mathrm{O}(309.1 \mathrm{mg}, 1.408 \mathrm{mmol})$ in DMSO $(30 \mathrm{~mL})$ was added a solution of 4-iodosalicylaldehyde (349.3 mg, $1.408 \mathrm{mmol}$ ) in DMSO (10 mL). The reaction mixture was stirred for $18 \mathrm{~h}$ and then filtered 
(fraction $1=215.8 \mathrm{mg}$ ). A second fraction of product was obtained by addition of $\mathrm{MeOH}(200 \mathrm{~mL})$ to the mother liquor which gave after filtration another fraction $(25.6 \mathrm{mg})$. Total yield: $241 \mathrm{mg}(0.203$ $\mathrm{mmol}, 58 \%$ ). This complex is almost insoluble in THF, DMF or DMSO. In order to analyze it by ${ }^{1} \mathrm{H}$ NMR, an additive (i.e., $\mathrm{NBu}_{4} \mathrm{OAc}$ ) was needed to solubilize it in DMSO. ${ }^{1} \mathrm{H} \mathrm{NMR}\left(500 \mathrm{MHz}\right.$, DMSO-d $\mathrm{d}^{6}+$ $\left.\mathrm{NBu}_{4} \mathrm{OAc}, 25^{\circ} \mathrm{C}\right) \delta 8.95\left(\mathrm{~s}, 4 \mathrm{H}, \mathrm{H}_{\mathrm{d}}\right), 8.14\left(\mathrm{~s}, 2 \mathrm{H}, \mathrm{H}_{\mathrm{e}}\right), 7.07\left(\mathrm{~d},{ }^{3} \mathrm{~J}=7.6 \mathrm{~Hz}, 4 \mathrm{H}, \mathrm{H}_{\mathrm{c}}\right), 7.03\left(\mathrm{~d},{ }^{4} \mathrm{~J}=1.7 \mathrm{~Hz}, 4 \mathrm{H}\right.$, $\left.\mathrm{H}_{\mathrm{a}}\right), 6.76\left(\mathrm{~d},{ }^{3} \mathrm{~J}=8.1 \mathrm{~Hz}, 4 \mathrm{H}, \mathrm{H}_{\mathrm{b}}\right) .{ }^{13} \mathrm{C}\left\{{ }^{1} \mathrm{H}\right\} \mathrm{NMR}\left(126 \mathrm{MHz}, \mathrm{DMSO}-\mathrm{d}^{6}+\mathrm{NBu}_{4} \mathrm{OAC}, 25^{\circ} \mathrm{C}\right) \delta 172.64\left(\mathrm{C}^{1}\right), 162.12$ $\left(C^{7}\right), 139.96\left(C^{8}\right), 137.38\left(C^{5}\right), 132.34\left(C^{2}\right), 121.32\left(C^{4}\right), 120.04\left(C^{6}\right), 104.34\left(C^{9}\right), 103.24\left(C^{3}\right)$. The signals corresponding to the additive $\left(\mathrm{NBu}_{4} \mathrm{OAC}\right)$ are not listed here. $\mathrm{MS}$ (MALDI+, DCTB): calcd for $\mathrm{C}_{34} \mathrm{H}_{18} \mathrm{l}_{4} \mathrm{~N}_{4} \mathrm{O}_{4} \mathrm{Zn}_{2}[\mathrm{M}]^{+}=1185.9$; found: 1185.9. Anal. Calcd for $\mathrm{C}_{34} \mathrm{H}_{18} \mathrm{l}_{4} \mathrm{~N}_{4} \mathrm{O}_{4} \mathrm{Zn}_{2} .1 \mathrm{H}_{2} \mathrm{O}$ : C, 33.95; $\mathrm{H}, 1.68$; $\mathrm{N}, 4.66$. Found: $\mathrm{C}, 33.26 ; \mathrm{H}, 1.20 ; \mathrm{N}, 4.56$. IR (KBr pellet): $v=1602 \mathrm{~s}, 1581 \mathrm{~s}, 1492 \mathrm{~s}, 1459 \mathrm{~m}, 1414 \mathrm{~m}$, 1383 m, 1298 w, 1246 w, 1199 w, 1171 m, 1136 w, 1064 w, 948 w, 915 m, 857 w, 777 w, 733 w, 584 w, 496 w. $\mathrm{cm}^{-1}$. UV-Vis (in THF with NBu $\left.4{ }_{4} \mathrm{OAc}\right)\left(\lambda[\mathrm{nm}], \varepsilon\left[\mathrm{M}^{-1} \mathrm{~cm}^{-1}\right]\right)$ (502 (sh), 58970; 480, 67270; 430, 50340; 330, 41930; 264, 46918).

2.1.2. Synthesis of complex 2: $\left[\left(\mu_{2}-1,2,4,5\right.\right.$-tetrakis( $N$-(4-iodosalicylidenealdiminato $\left.)\right)$ benzene)bis(N,Ndimethylformamide)-di-zinc(ii)]

To a solution of 1,2,4,5-tetraaminobenzene tetrahydrochloride (100 mg, $0.352 \mathrm{mmol}$ ) and $\mathrm{Zn}(\mathrm{OAc})_{2} .2 \mathrm{H}_{2} \mathrm{O}(309.1 \mathrm{mg}, 1.408 \mathrm{mmol})$ in DMSO $(30 \mathrm{~mL})$ was added a solution of 5-iodosalicylaldehyde $(349.3 \mathrm{mg}, 1.408 \mathrm{mmol})$ in DMSO $(10 \mathrm{~mL})$. The reaction mixture was stirred for $18 \mathrm{~h}$ and then filtered (fraction $1=231.8 \mathrm{mg}$ ). A second fraction of product was obtained by addition of $\mathrm{MeOH}(200 \mathrm{~mL})$ to the mother liquor which gave after filtration another fraction $(50.4 \mathrm{mg})$. Total yield: $282 \mathrm{mg}(0.238$ $\mathrm{mmol}, 68 \%)$. This complex is almost insoluble in THF, DMF or DMSO. In order to analyze it by ${ }^{1} \mathrm{H} N M R$, an additive (i.e., $\mathrm{NBu}_{4} \mathrm{OAc}$ ) was needed to solubilize it in DMF. ${ }^{1} \mathrm{H} \mathrm{NMR}\left(500 \mathrm{MHz}\right.$, DMF-d $\mathrm{d}^{7}+\mathrm{NBu}_{4} \mathrm{OAc}$, $\left.25^{\circ} \mathrm{C}\right) \delta 9.08\left(\mathrm{~s}, 4 \mathrm{H}, \mathrm{H}_{\mathrm{d}}\right), 8.35\left(\mathrm{~s}, 2 \mathrm{H}, \mathrm{H}_{\mathrm{e}}\right), 7.64\left(\mathrm{~d},{ }^{4} \mathrm{~J}=2.6 \mathrm{~Hz}, 4 \mathrm{H}, \mathrm{H}_{\mathrm{c}}\right), 7.35\left(\mathrm{~d},{ }^{3} \mathrm{~J}=9.0,2.5 \mathrm{~Hz}, 4 \mathrm{H}, \mathrm{H}_{\mathrm{a}}\right), 6.52$ $\left(\mathrm{d},{ }^{3} \mathrm{~J}=8.1 \mathrm{~Hz}, 4 \mathrm{H}, \mathrm{H}_{\mathrm{b}}\right) \cdot{ }^{13} \mathrm{C}\left\{{ }^{1} \mathrm{H}\right\} \mathrm{NMR}\left(126 \mathrm{MHz}, \mathrm{DMD}-\mathrm{d}^{7}+\mathrm{NBu}_{4} \mathrm{OAc}, 25^{\circ} \mathrm{C}\right) \delta 172.73\left(\mathrm{C}_{1}\right), 160.98\left(\mathrm{C}_{7}\right)$, $143.50\left(C_{5}\right), 141.19\left(C_{3}\right), 140.30\left(C_{8}\right), 126.50\left(C_{2}\right), 123.49\left(C_{6}\right), 104.04\left(C_{9}\right), 69.79\left(C_{4}\right)$. The signals corresponding to the additive ( $\mathrm{NBu}_{4} \mathrm{OAC}$ ) are not listed here. MS (MALDI+, DCTB): calcd for $\mathrm{C}_{34} \mathrm{H}_{18} \mathrm{I}_{4} \mathrm{~N}_{4} \mathrm{O}_{4} \mathrm{Zn}_{2}[\mathrm{M}]^{+}=1185.9$; found: 1185.9. Anal. Calcd for $\mathrm{C}_{34} \mathrm{H}_{18} \mathrm{l}_{4} \mathrm{~N}_{4} \mathrm{O}_{4} \mathrm{Zn}_{2} .1 \mathrm{H}_{2} \mathrm{O}: \mathrm{C}, 33.95 ; \mathrm{H}, 1.68$; $\mathrm{N}$, 4.66. Found: $\mathrm{C}, 33.13 ; \mathrm{H}, 1.17 ; \mathrm{N}, 4.59$. IR ( $\mathrm{KBr}$ pellet): $v=1606 \mathrm{~s}, 1510 \mathrm{~s}, 1491 \mathrm{~m}, 1456 \mathrm{~s}, 1406 \mathrm{~m}$, 1374 m, 1305 m, 1246 w, 1164 s, 948 w, 872 w, 829 m, 783 w, 625 m, 557 w, 496 w. cm-

\subsection{X-Rays study}

The crystallographic data of compound 1 were collected at 193(2) K using a Bruker-AXS D8-Venture diffractometer equipped with a CMOS detector (Photon 100) and a $30 \mathrm{~W}$ air-cooled microfocus source using $\mathrm{Cu} \mathrm{K \alpha}$ radiation $(\lambda=1.54178 \AA$ ). Phi- and omega-scans were used. The space group was determined on the basis of systematic absences and intensity statistics. Semi-empirical absorption correction was employed. [24] The structure was solved using an intrinsic phasing method (SHELXT), [25] and refined using the least-squares method on F2. [26] All non-H atoms were refined with anisotropic displacement parameters. Hydrogen atoms were refined isotropically at calculated positions using a riding model with their isotropic displacement parameters constrained to be equal to 1.5 times the equivalent isotropic displacement parameters of their pivot atoms for terminal sp3 carbon and 1.2 times for all other carbon atoms. A counter cation $\mathrm{NtBu}^{4+}$ is partially disordered: equal xyz and Uij constraints (EXYZ and EADP) and several restraints (SAME, SIMU, DELU) were applied to model the disorder over 2 positions. Hydrogen atoms of the $\mathrm{H}_{2} \mathrm{O}$ molecule were located by difference Fourier map and were refined using restraints DFIX and SADI to get suitable target values. 
Selected data for 1 : $\mathrm{C}_{34} \mathrm{H}_{18} \mathrm{Br}_{2} \mathrm{l}_{4} \mathrm{~N}_{4} \mathrm{O}_{4} \mathrm{Zn}_{2}, 4\left(\mathrm{C}_{16} \mathrm{H}_{36} \mathrm{~N}\right), 2 \mathrm{Br}, 2\left(\mathrm{H}_{2} \mathrm{O}\right) \mathrm{M}=2510.36$, triclinic, space group $P \overline{1}, a=10.9172(3) \AA, b=17.1431(5) \AA, c=17.1840(5) \AA, \alpha=117.6852(13)^{\circ}, \beta=103.5977(16)^{\circ}, \gamma=$ $90.8450(16)^{\circ}, V=2739.18(14) \AA^{3}, Z=1$, crystal size $0.25 \times 0.08 \times 0.04 \mathrm{~mm}^{3}, 37748$ reflections collected (9683 independent, Rint $=0.0560$ ), 636 parameters, 259 restraints, $R 1[I>2 \sigma(I)]=0.0368, w R 2$ [all data] $=0.0901$, largest diff. peak and hole: 1.819 and $-0.836 \mathrm{e}^{-3}$.

3. Results and discussion

\subsection{NMR analysis}

Complexes 1-2 (scheme 1) are sparingly soluble under non-polar conditions. The NMR analysis was therefore made under polar conditions (DMSO- $d^{6}$ for 1 and DMF- $d^{7}$ for 2) with a necessary additive agent ( $\mathrm{NBu}_{4} \mathrm{OAc}$ ). The analysis confirms the proposed connectivity patterns ( $c f$ Figure 1 and Figures S1S3). The numbering system used for the assignments of signals is provided in Figure 1 and in the Supporting Information.

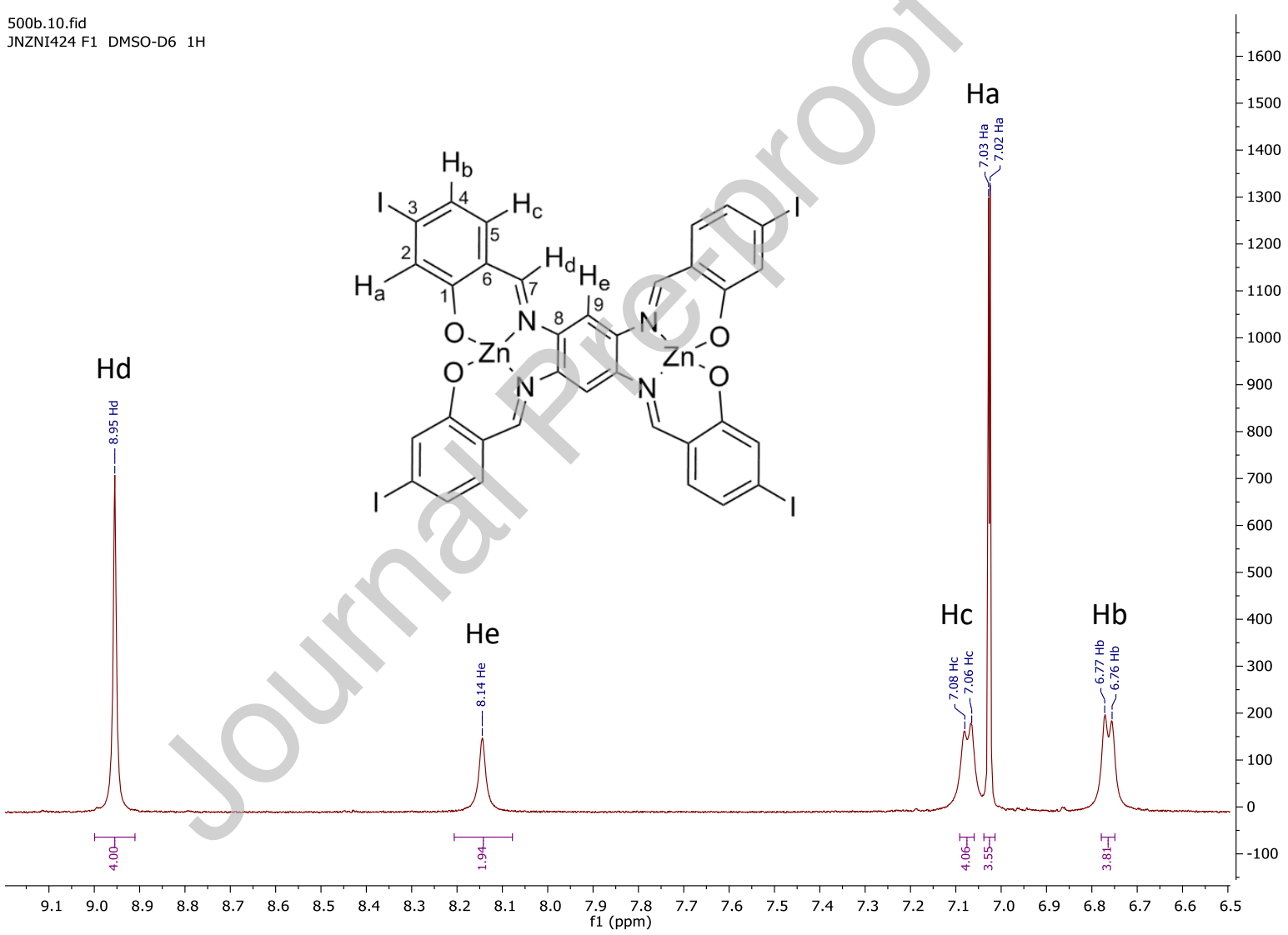

Figure 1: Complex 1: ${ }^{1} \mathrm{H}$ NMR $\left(500 \mathrm{MHz}, \mathrm{DMSO}-\mathrm{d}^{6}, 25^{\circ} \mathrm{C}\right)$ (aromatic region)

\subsection{Thermogravimetric analysis}

Thermogravimetric analysis (TGA) are used up to $1000^{\circ} \mathrm{C}$ at He atmosphere to investigate the thermal stability of complexes $\mathbf{1}$ and $\mathbf{2}$. The measurements reveal that the complex $\mathbf{1}$ and complex $\mathbf{2}$ are stable up to approximatively $400^{\circ} \mathrm{C}$ and $300^{\circ} \mathrm{C}$ respectively. The thermogravimetric plots (TGA and DTG) of complexes $\mathbf{1}$ and $\mathbf{2}$ as weight loss versus temperature are shown in supplementary materials (Figures S4-S5). The thermal decomposition of the two complexes essentially takes place in one stage. This 
stage is probably related to the omission of the four bromine atoms with a mass loss of $53 \%$ for 1 at $420^{\circ} \mathrm{C}$ and $45 \%$ for 2 at $380^{\circ} \mathrm{C}$ compared to the calculated $43 \%$ for both complexes.

\subsection{FT-IR Spectra}

The experimental IR spectra of the complexes $\mathbf{1}$ and $\mathbf{2}$ are shown Figure 2. These spectra look almost identical except at low frequencies (around $600 \mathrm{~cm}^{-1}$ and $800 \mathrm{~cm}^{-1}$ ). The calculated spectra (Figure 3) are in close agreement with the experimental ones. Indeed, the experimental observed differences between complexes $\mathbf{1}$ and $\mathbf{2}$ at low frequencies are also observed on the theoretical spectra. In order to get the calculated IR spectra, the optimized geometry of complex $\mathbf{1}$ and complex $\mathbf{2}$ have been obtained using Density Functional Theory (DFT) with Gaussian09 software [27] using PBE0 functional.[28] All atoms were described using a double zeta quality basis set (LANL2DZ).[29]

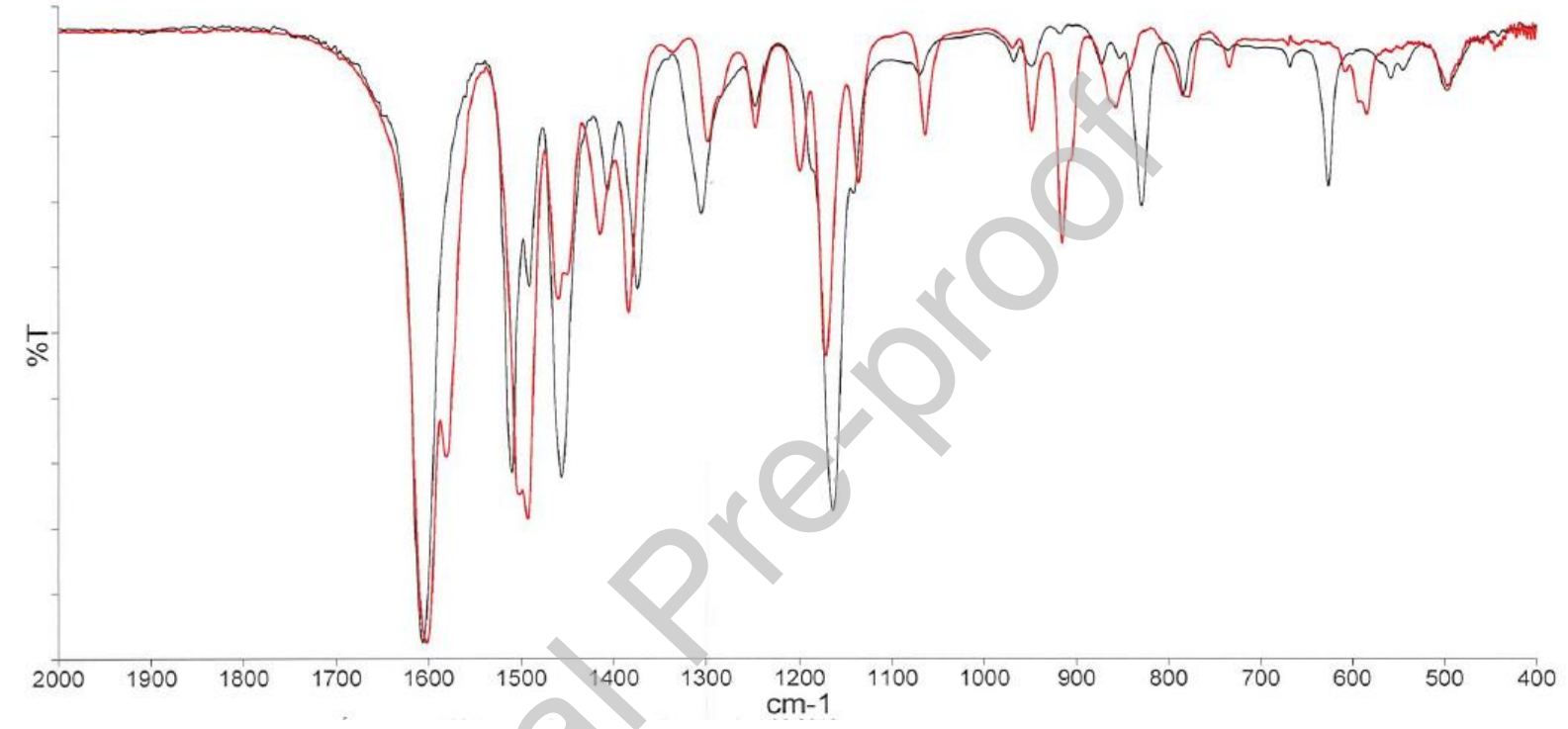

Figure 2: Experimental IR spectra of complex 1 (black) and complex 2 (red) $\left(2000-400 \mathrm{~cm}^{-1}\right)$

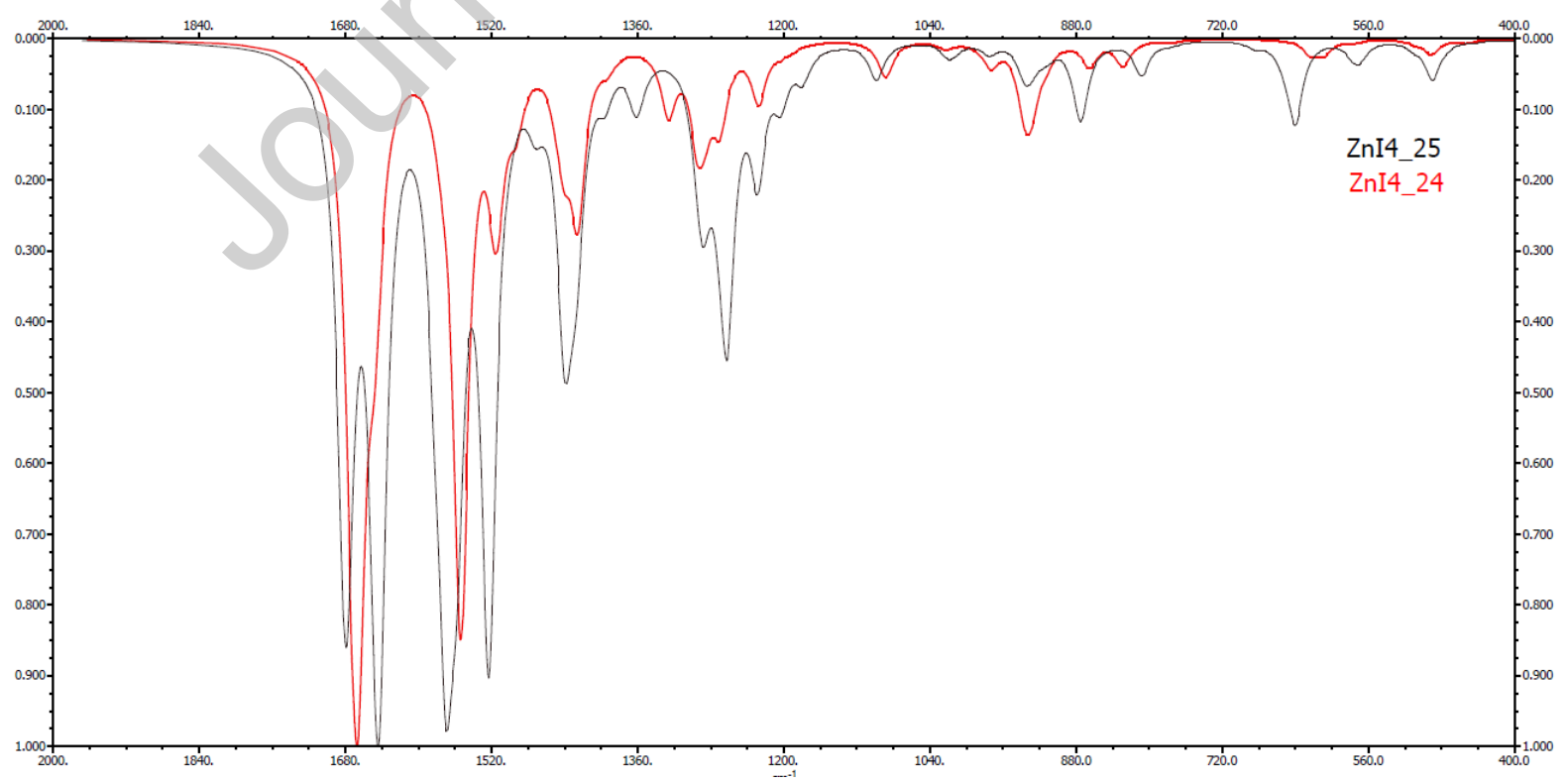

Figure 3: Calculated IR spectra of complex 1 (black) and complex 2 (red) $\left(2000-400 \mathrm{~cm}^{-1}\right)$

\subsection{UV-Vis Analysis}


The experimental UV-vis spectrum of complex $\mathbf{1}$ is shown in Figure 4. The spectrum was taken in THF with an additive agent $\left(\mathrm{NBu}_{4} \mathrm{Br}\right)$ in order to increase the solubility. In the UV-Vis range, it shows five peaks as follows: $502 \mathrm{~nm}$ (shoulder), $480 \mathrm{~nm}$ (strong), $430 \mathrm{~nm}$ (medium), $330 \mathrm{~nm}$ (medium) and 264nm (medium). It has to be noted that the same spectrum is obtained in DMSO with $\mathrm{NBu}_{4} \mathrm{OAc}$ as additive agent.

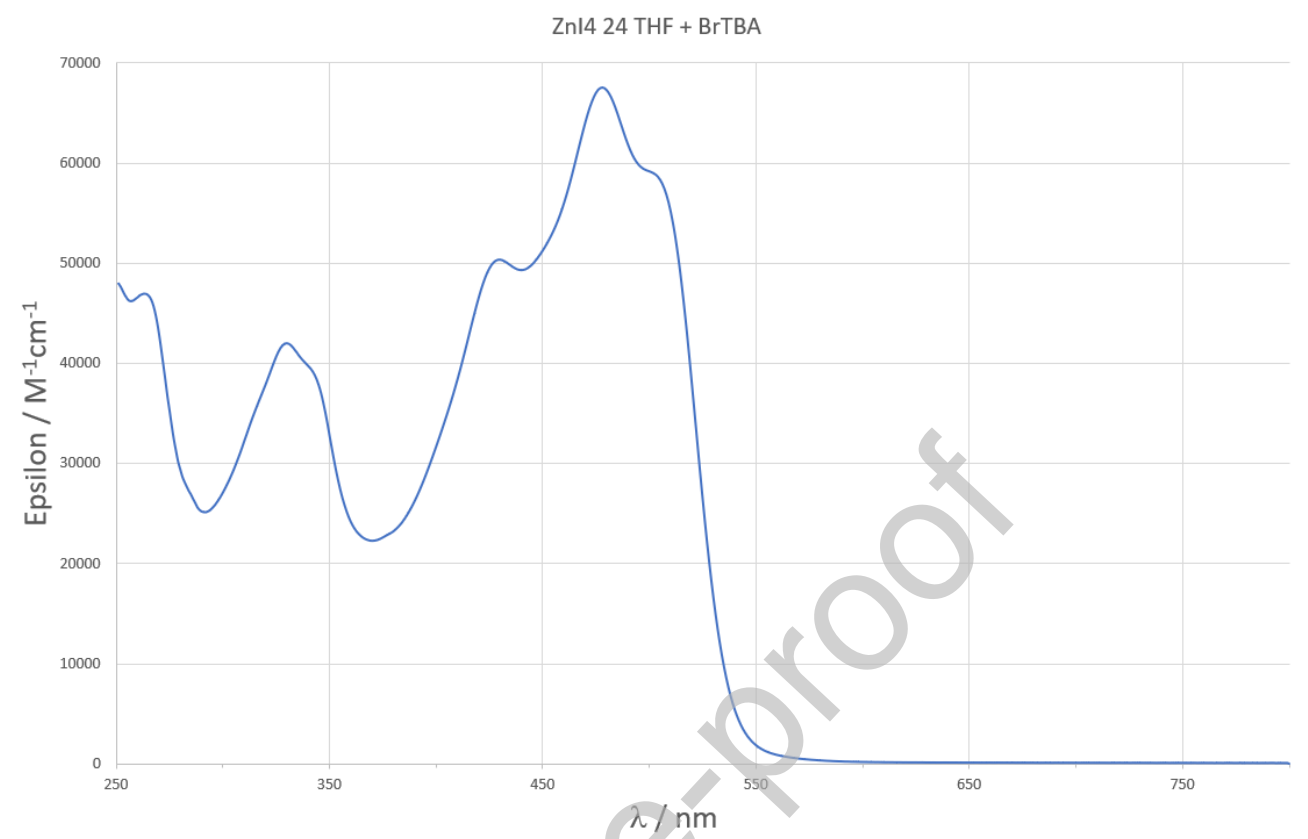

Figure 4: Experimental UV-Vis spectrum of complex 1 in $\mathrm{THF}$ with $\left(\mathrm{NBu}_{4} \mathrm{Br}\right)$ as additive agent.

\subsection{X-Rays analysis}

The X-Ray molecular structure of complex 1 is shown in Figure 5 and Figures S6-S7. Crystals suitable for single-crystal XRD were obtained by adding an additive $\left(\mathrm{NBu}_{4} \mathrm{Br}\right)$ to a solution of complex $\mathbf{1}$ in THF. As a consequence, one bromine atom of the additive appears to bind to one molecular central zinc atom. Complex 1 crystallizes in a triclinic lattice and its asymmetric unit comprises one half of a centrosymmetric dinuclear complex, a tetrabutylammonium cation, a molecule of $\mathrm{NBu}_{4} \mathrm{Br}$ and a water molecule coming from the chemical reaction medium. The coordination geometry can be viewed as a distorted five-coordinated square pyramid with a $\tau_{5}$ value [30] of 0.14 , fairly close to the value of 0 for an ideal square pyramid. The axial site is occupied by the $\mathrm{Zn}$ atom, its deviation from the mean plane defined by $\mathrm{O} 1, \mathrm{O} 2, \mathrm{~N} 1$ and $\mathrm{N} 2$ is $0.5478(6) \AA$. . The Zn-O and Zn-N distances Zn1-O1, Zn1-O2, Zn1-N1 and $\mathrm{Zn} 1-\mathrm{N} 2$ found within the salphen complex are similar to other bis-salphen zinc complexes described [1.985(3), 1.995(3), 2.123(3) and 2.108(3) Å respectively]. [22, 31, 32] The C1-C6 ring is almost coplanar with the central phenyl ring $\mathrm{C} 15-\mathrm{C} 17 \mathrm{~A}$ (tilting angle of $4.56^{\circ}$ ) whereas the $\mathrm{C} 8-\mathrm{C} 13$ is tilted by $12.8^{\circ}$. Only the anionic part of the complex 1 is represented in Figure 5 for clarity. Crystallographic data are shown on Supplementary materials. 


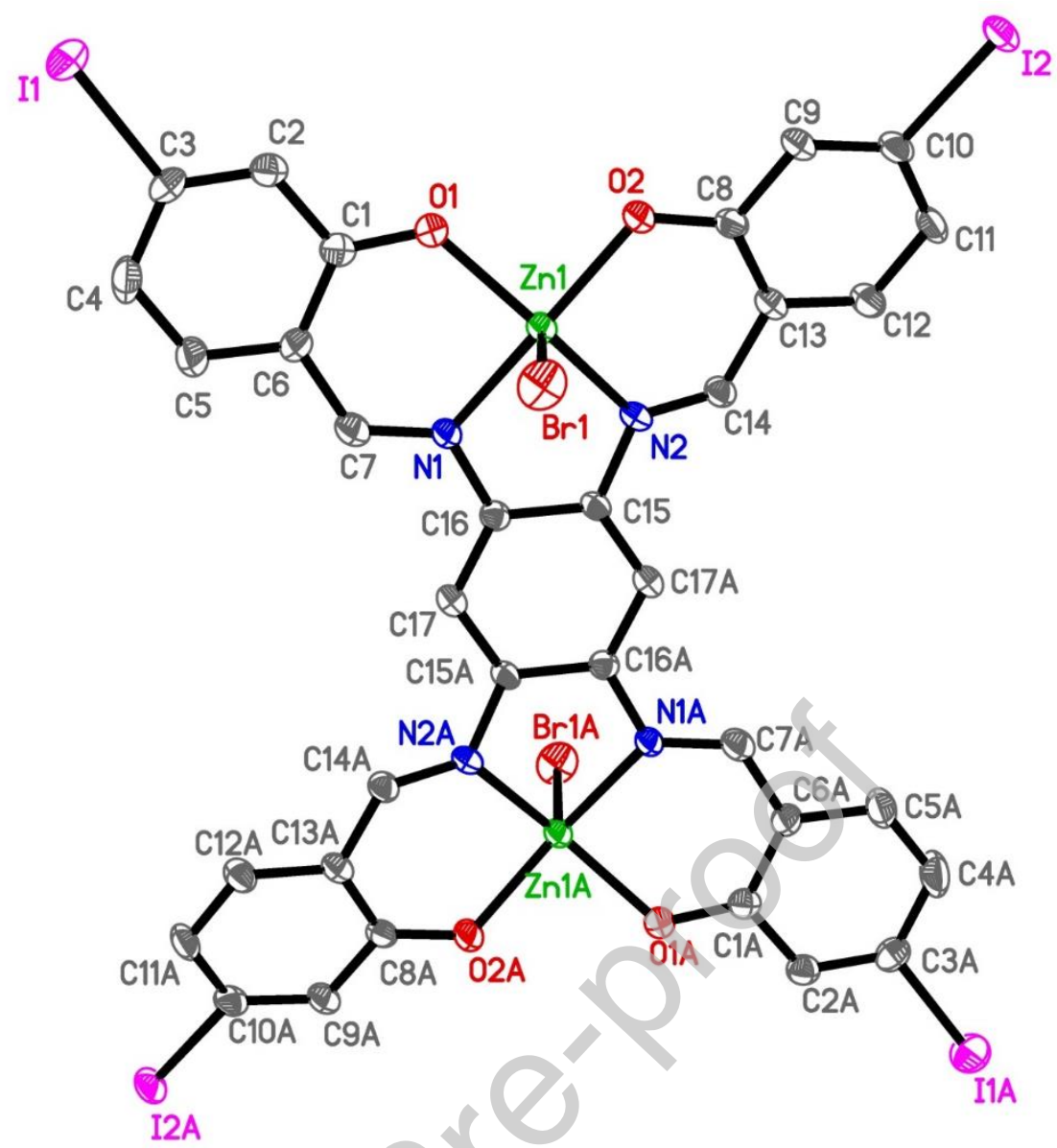

Figure 5: Molecular view of anionic part of the complex 1. Thermal ellipsoids represent $50 \%$ probability level. $\mathrm{H}$ and disordered atoms are omitted for clarity.

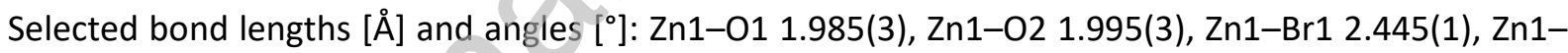
N1 2.123(3), Zn1-N2 2.108(3); O1-Zn1-O2 89.69(6), O1-Zn1-N1 87.89(12), O1-Zn1-N2 144.02(13), O2-Zn1-N1 152.40(13), O2-Zn1-N2 89.07(12), N1-Zn1-N2 77.12(12) O1-Zn1-Br1 105.34(9), O2-Zn1Br1 107.23(10), N2-Zn1-Br1 109.33(9), N1-Zn1-Br1 99.92(9)

\section{Conclusions}

In conclusion, two new iodo derivatives of bis-salphen zinc complexes have been synthesized and fully characterized. These molecules, stable at room temperature, quite easy to make, chemically pure, readily available, will in the future be used as molecular building block to engineer novel twodimensional halogen-bonded self-assembled nanoarchitecture.

CCDC-1951509 (1) contains the supplementary crystallographic data for this paper. These data can be obtained free of charge from The Cambridge Crystallographic Data Centre via www.ccdc.cam.ac.uk/data request/cif.

\section{ORCID}

Jacques Bonvoisin: 0000-0003-3741-9529

Fabien Silly: 0000-0001-6782-9268

Nathalie Saffon-Merceron: 0000-0002-0301-4163 


\section{Author statement}

Mélia Lacaze : Investigation; Nathalie Saffon-Merceron : Investigation, Formal analysis ; Fabien Silly : Conceptualization ; Jacques Bonvoisin : Conceptualization, Writing - Review \& Editing, Validation, Supervision

\section{Declaration of interests}

$\bigotimes$ The authors declare that they have no known competing financial interests or personal relationships that could have appeared to influence the work reported in this paper

\section{Acknowledgements}

This work was supported by the Centre National de la Recherche Scientifique (CNRS). It has received funding in part from the Agence Nationale de la Recherche (ANR) (MQwires PRCI Taiwan-France). This work was granted access to the HPC resources of CALMIP under the allocation 2012-[1206]. The authors thank David Neumeyer (CEMES) for recording TGA spectra, Pierre Lavedan and Marc Vedrenne of the Institute de Chimie de Toulouse ICT-FR 2599 (Universite de Toulouse, CNRS, Toulouse, France www.ict.ups-tlse.fr) for recording NMR spectra. Technical assistance for MS measurements provided by Valérie Bourdon of the ICT-FR 2599 - (Toulouse, France - ict.ups-tlse.fr) is gratefully acknowledged. We acknowledge the financial support by the European Fund for Regional Development POCTEFA through Project EFA194/16/TNSI.

\section{References}

[1] G. Salassa, M.J.J. Coenen, S.J. Wezenberg, B.L.M. Hendriksen, S. Speller, J. Elemans, A.W. Kleij, Extremely Strong Self-Assembly of a Bimetallic Salen Complex Visualized at the Single-Molecule Level, Journal of the American Chemical Society, 134 (2012) 7186-7192.

[2] M.T. Raisanen, F. Mogele, S. Feodorow, B. Rieger, U. Ziener, M. Leskela, T. Repo, Alkyl chain length defines $2 \mathrm{D}$ architecture of salophen complexes on liquid-graphite interface, European Journal of Inorganic Chemistry, (2007) 4028-4034.

[3] Y.C. Zhang, B. Chilukuri, T.B. Hanson, Z.M. Heiden, D.Y. Lee, Connecting Solution-Phase to SingleMolecule Properties of Ni(Salophen), Journal of Physical Chemistry Letters, 10 (2019) 3525-3530.

[4] L. Mengozzi, M. El Garah, A. Gualandi, M. Iurlo, A. Fiorani, A. Ciesielski, M. Marcaccio, F. Paolucci, P. Samori, P.G. Cozzi, Phenoxyaluminum(salophen) Scaffolds: Synthesis, Electrochemical Properties, and Self-Assembly at Surfaces of Multifunctional Systems, Chemistry-a European Journal, 24 (2018) 11954-11960.

[5] M. Bazarnik, B. Bugenhagen, M. Elsebach, E. Sierda, A. Frank, M.H. Prosenc, R. Wiesendanger, Toward Tailored All-Spin Molecular Devices, Nano Letters, 16 (2016) 577-582.

[6] A. DiLullo, S.H. Chang, N. Baadji, K. Clark, J.P. Klockner, M.H. Prosenc, S. Sanvito, R. Wiesendanger, G. Hoffmann, S.W. Hla, Molecular Kondo Chain, Nano Letters, 12 (2012) 3174-3179.

[7] M. Viciano-Chumillas, D.Z. Li, A. Smogunov, S. Latil, Y.J. Dappe, C. Barreteau, T. Mallah, F. Silly, Tailoring the Structure of Two-Dimensional Self-Assembled Nanoarchitectures Based on Ni-II-Salen Building Blocks, Chemistry-a European Journal, 20 (2014) 13566-+.

[8] C.J. Whiteoak, G. Salassa, A.W. Kleij, Recent advances with pi-conjugated salen systems, Chemical Society Reviews, 41 (2012) 622-631.

[9] A.W. Kleij, M. Kuil, D.M. Tooke, M. Lutz, A.L. Spek, J.N.H. Reek, Zn-II-salphen complexes as versatile building blocks for the construction of supramolecular box assemblies, Chemistry-a European Journal, 11 (2005) 4743-4750. 
[10] S.J. Wezenberg, A.W. Kleij, Material applications for salen frameworks, Angewandte ChemieInternational Edition, 47 (2008) 2354-2364.

[11] J.A. Gardener, O.Y. Shvarova, G.A.D. Briggs, M.R. Castell, Intricate Hydrogen-Bonded Networks: Binary and Ternary Combinations of Uracil, PTCDI, and Melamine, Journal of Physical Chemistry C, 114 (2010) 5859-5866.

[12] F. Silly, A.Q. Shaw, M.R. Castell, G.A.D. Briggs, M. Mura, N. Martsinovich, L. Kantorovich, Melamine structures on the Au(111) surface, Journal of Physical Chemistry C, 112 (2008) 1147611480.

[13] Y.L. Yang, C. Wang, Hierarchical construction of self-assembled low-dimensional molecular architectures observed by using scanning tunneling microscopy, Chemical Society Reviews, 38 (2009) 2576-2589.

[14] S. Uemura, M. Aono, T. Komatsu, M. Kunitake, Two-Dimensional Self-Assembled Structures of Melamine and Melem at the Aqueous Solution-Au(111) Interface, Langmuir, 27 (2011) 1336-1340.

[15] G. Berger, J. Soubhye, F. Meyer, Halogen bonding in polymer science: from crystal engineering to functional supramolecular polymers and materials, Polym Chem-Uk, 6 (2015) 3559-3580.

[16] F. Silly, Selecting Two-Dimensional Halogen Halogen-Bonded Self-Assembled 1,3,5-Tris(4iodophenyl)benzene Porous Nanoarchitectures at the Solid-Liquid Interface, Journal of Physical Chemistry C, 117 (2013) 20244-20249.

[17] F. Silly, Concentration-Dependent Two-Dimensional Halogen-Bonded Self-Assembly of 1,3,5Tris(4-iodophenyl)benzene Molecules at the Solid-Liquid Interface, Journal of Physical Chemistry C, 121 (2017) 10413-10418.

[18] L. Dong, P.N. Liu, N. Lin, Surface-Activated Coupling Reactions Confined on a Surface, Accounts Chem Res, 48 (2015) 2765-2774.

[19] Q.T. Fan, J.M. Gottfried, J.F. Zhu, Surface-Catalyzed C-C Covalent Coupling Strategies toward the Synthesis of Low-Dimensional Carbon-Based Nanostructures, Accounts Chem Res, 48 (2015) 24842494.

[20] D. Peyrot, F. Silly, On-Surface Synthesis of Two-Dimensional Covalent Organic Structures versus Halogen-Bonded Self-Assembly: Competing Formation of Organic Nanoarchitectures, Acs Nano, 10 (2016) 5490-5498.

[21] F. Silly, C. Viala, J. Bonvoisin, Two-Dimensional Halogen-Bonded Porous Self-Assembled Nanoarchitectures of Copper beta-Diketonato Complexes, Journal of Physical Chemistry C, 122 (2018) 17143-17148.

[22] E.C. Escudero-Adan, M.M. Belmonte, E. Martin, G. Salassa, J. Benet-Buchholz, A.W. Kleij, A Short Desymmetrization Protocol for the Coordination Environment in Bis-salphen Scaffolds, Journal of Organic Chemistry, 76 (2011) 5404-5412.

[23] K.L. Kuo, C.C. Huang, Y.C. Lin, Synthesis and photophysical properties of multinuclear zincsalophen complexes: enhancement of fluorescence by fluorene termini, Dalton Transactions, (2008) 3889-3898.

[24] Bruker, SADABS, Bruker AXS Inc., in, Madison, Wisconsin, USA, 2008.

[25] ShelXT, G.M. Sheldrick, University of Göttingen, Acta Crystallogr. Sect A, 71 (2015) 3-8.

[26] ShelXL, G.M. Sheldrick, University of Göttingen, Acta Crystallogr. Sect C, 71 (2015) 3-8.

[27] M.J. Frisch, G.W. Trucks, H.B. Schlegel, G.E. Scuseria, M.A. Robb, J.R. Cheeseman, G. Scalmani, V. Barone, B. Mennucci, G.A. Petersson, H. Nakatsuji, M. Caricato, X. Li, H.P. Hratchian, A.F. Izmaylov, J. Bloino, G. Zheng, J.L. Sonnenberg, M. Hada, M. Ehara, K. Toyota, R. Fukuda, J. Hasegawa, M. Ishida, T. Nakajima, Y. Honda, O. Kitao, H. Nakai, T. Vreven, J. Montgomery, J. A., J.E. Peralta, F. Ogliaro, M. Bearpark, J.J. Heyd, E. Brothers, K.N. Kudin, V.N. Staroverov, R. Kobayashi, J. Normand, K. Raghavachari, A. Rendell, J.C. Burant, S.S. Iyengar, J. Tomasi, M. Cossi, N. Rega, J.M. Millam, M. Klene, J.E. Knox, J.B. Cross, V. Bakken, C. Adamo, J. Jaramillo, R. Gomperts, R.E. Stratmann, O. Yazyev, A.J. Austin, R. Cammi, C. Pomelli, J.W. Ochterski, R.L. Martin, K. Morokuma, V.G. Zakrzewski, G.A. Voth, P. Salvador, J.J. Dannenberg, S. Dapprich, A.D. Daniels, Ö. Farkas, J.B. Foresman, J.V. Ortiz, J. Cioslowski, D.J. Fox, Gaussian09, in, Gaussian, Inc., Wallingford CT, 2013. 
[28] C. Adamo, V. Barone, Toward reliable density functional methods without adjustable parameters: The PBEO model, J Chem Phys, 110 (1999) 6158-6170.

[29] T.H. Dunning, P.J. Hay, Modern Theoretical Chemistry, in: H.F. Schaefer (Ed.), Plenum, New York, 1976, pp. 1-28.

[30] A.W. Addison, T.N. Rao, J. Reedijk, J. Vanrijn, G.C. Verschoor, Synthesis, Structure, and Spectroscopic Properties of Copper(li) Compounds Containing Nitrogen Sulfur Donor Ligands - the Crystal and Molecular-Structure of Aqua[1,7-Bis(N-Methylbenzimidazol-2'-YI)-2,6-

Dithiaheptane]Copper(Ii) Perchlorate, J Chem Soc Dalton, (1984) 1349-1356.

[31] W.S. Kim, K.Y. Lee, E.H. Ryu, J.M. Gu, Y. Kim, S.J. Lee, S. Huh, Catalytic Transesterifications by a Zn-BisSalen MOF Containing Open Pyridyl Groups Inside 1D Channels, European Journal of Inorganic Chemistry, 2013 (2013) 4228-4233.

[32] S.J. Wezenberg, G. Salassa, E.C. Escudero-Adan, J. Benet-Buchholz, A.W. Kleij, Effective Chirogenesis in a Bis(metallosalphen) Complex through Host-Guest Binding with Carboxylic Acids, Angewandte Chemie-International Edition, 50 (2011) 713-716.

Graphical abstract:

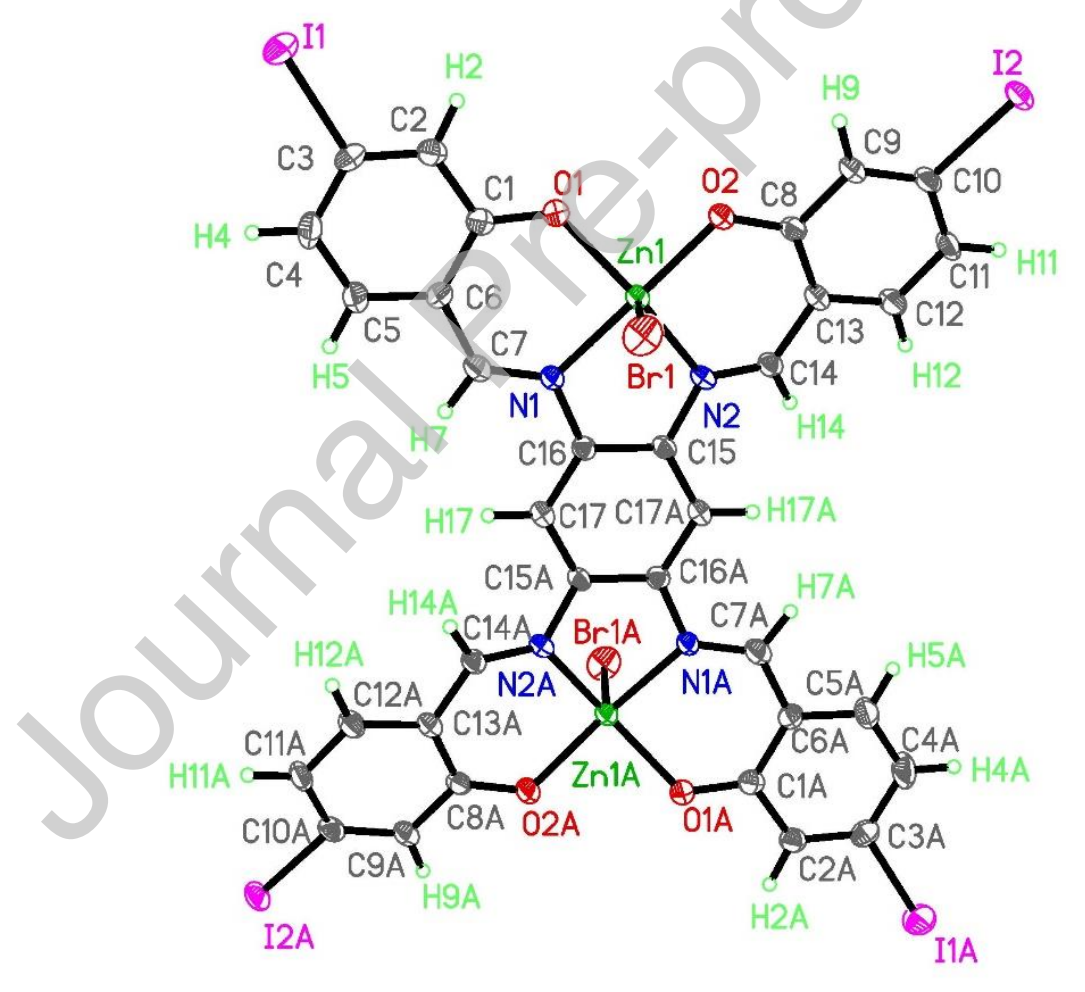

